\title{
Assessment of Exclusive Breastfeeding Among Working Mothers in Tertiary Institutions (A Case Study of Imo State)
}

\author{
Afam-Anene Olivia Chinyere \\ Department of Nutrition and Dietetics, Faculty of Health Sciences, Imo State University, Owerri, Imo State, Nigeria
}

\section{Osita-Njoku Agnes}

Department of Sociology, Faculty of Social Sciences, Imo State University, Owerri, Imo State, Nigeria
Article History

Received: October 7, 2020

Revised: November 25, 2020

Accepted: November 27, 2020

Published: November 29, 2020

\author{
Ajaegbu Odinaka Okechukwu* \\ Department of Sociology, Faculty of Social Sciences, Imo State University, Owerri, Imo State, Nigeria \\ Email: ajaegbuodina@yahoo.com
}

\begin{abstract}
Globally, the practice of exclusive breastfeeding has been recognized as an important public health strategy for reducing infant and child morbidity and mortality. While studies have shown that many newborns in Nigeria are still fed with something other than breast milk despite the numerous health benefits of exclusive breastfeeding, there is little information on why the practice of exclusive breastfeeding is low among the educated. This study therefore assessed the practices of exclusive breastfeeding among working mothers in tertiary institutions in Imo State. Mixed research design and multi-stage sampling method were used for this study. For the quantitative data, 912 copies of questionnaire were administered and analyzed using descriptive and inferential statistics while 20 in-depth interviews were conducted for the qualitative data and analyzed using content analysis method. It was found that spouse educational level is positively correlated with practice of exclusive breastfeeding. Short duration of maternity leave and inconvenient working environment were major factors that undermine exclusive breastfeeding practice among working mothers. In conclusion, while exclusive breastfeeding awareness is high, many working mothers do not practice it. Consequently, employers should increase paid maternity leave to minimum of six months and make work environment to be conducive for breastfeeding mothers and their babies.
\end{abstract}

Keywords: Exclusive breastfeeding; Health; Working mothers; Working environment.

\section{Introduction}

Recent time, the world has witnessed some conscious efforts to improve the health of children even from conception. According to World Health Organization WHO (2018) almost 7 million children who are less than five years die globally each year, mainly from preventable causes with new-born deaths nearly representing half of all deaths under five years. Sub-Saharan Africa has the highest under-five mortality rate in the world, and children are more than 15 times likely to die before the age of five; with over $45 \%$ of these deaths linked to malnutrition (World Health Organization WHO, 2018). This high burden of childhood morbidity and mortality according to Black et al. (2013) is associated with inadequate infant and young child feeding practices.

The early years of a child's life are very crucial in laying the foundation of good health. At this stage certain specific biological and psycho-social needs must be met to ensure the survival and healthy development of the child (Allen et al., 2005). One of these vital needs is to ensure that infants and young children get a nutritious and healthy start in life through breastfeeding. Breastfeeding has long been recognized as an important public health strategy for reducing infant and child morbidity and mortality, reducing maternal morbidity and for controlling healthcare cost (Al-Binali, 2012). Therefore, medical and nutritional experts have recommended exclusive breastfeeding for at least the first six months (National Population Commission NPC, 2019; UNICEF, 2015) and continuous breastfeeding for at least one year of an infant life (Allen et al., 2005) in addition to complementary feeding.

The Global Health Observatory (GHO) in the year 2015 reported that the global rate of exclusive breastfeeding is still low (37\%) despite its numerous benefits, specifically in the western pacific, where fewer than one out of three infants below six months old is exclusively breastfed (Global Health Observatory, 2015). In Africa, more than 95\% of infants are currently breastfed, but the feeding practices are often inadequate (Global Health Observatory, 2015). The rate of bottle-feeding is high in countries (exceeding 30\% in Tunisia, Nigeria, Namibia and Sudan) where mother education, short maternity leave, inconvenient working environment tend to shorten breastfeeding (Dop, 2002). For example, the 2013 Nigeria Demographic and Health Survey data revealed that though almost all babies (98\%) were breastfed in Nigeria, only a minority of mothers (33\%) achieved the WHO recommended initiation within one hour of birth and only $17 \%$ continued to breastfeed for six months. The survey further revealed that $70 \%$ of the newborn at home were fed with something other than breast milk during the first three (3) days, of life compared to the $40 \%$ newborn in health facilities (National Population Commission NPC, 2013). 


\section{Sumerianz Journal of Social Science}

Over the last two decades, there has been a growing attention in the endorsement of exclusive breastfeeding as a recommended feeding practice for newborns (Danso, 2014). In order to encourage exclusive breastfeeding and reduce infant mortality, the International Labour Organization (ILO) recommended a period of not less than 14 weeks for maternity leave (Maternity Protection Convention, 2000). This is in recognition of the numerous long and short health benefits exclusive breastfeeding confers on both mothers and infants. Yet, studies on working mothers in Nigeria have shown that despite the numerous health benefits of exclusive breastfeeding on mothers and infants, newborns are still fed with something other than breast milk (Adebayo et al., 2014; Ekanem et al., 2012) even among the educated (National Population Commission NPC, 2013).

In a study examining breastfeeding knowledge and practice of mothers with infants less than six months old in Kosofe Local Government of Lagos State, Adebayo et al. (2014) revealed that while there was no significant relationship between educational level and practice of exclusive breastfeeding, only $8.4 \%$ of mothers in the study area practiced exclusive breastfeeding. In Imo State according to 2013 National Demographic Health Survey, only $18 \%$ of working women in the State practiced exclusive breastfeeding (National Population Commission NPC, 2013) despite the high level of education attainment the State population is known for, health benefits of exclusive breastfeeding and the high profile campaign of the baby friendly hospital initiative in the State.

According to Forbes et al. (2003), lack of suitable facilities outside of the home and at work place, inconvenience, conflicts at work, family pressure, ignorance and the need to return to work are some factors responsible for the low practice of exclusive breastfeeding among working mothers. Fein and Roe (2005) reported inconvenient working environment of the mother, lack of knowledge and awareness as some of the factors that affect the practice of exclusive breastfeeding amongst working mothers. This was also corroborated by Yi-Chun et al. (2006) in their article titled "Effects of Work Related Factors on the Breastfeeding Behaviour of Working Mothers". The authors revealed that low percentage of starting or continuing to breastfeed was partly because of an inconvenient working environment (Yi-Chun et al., 2006). Omuemu and Adamu (2019), added that poor spousal support, no paid maternity leave and non-availability of nearby crèches are factors that negatively affect the practice of exclusive breastfeeding. While studies have identified inconvenient working environment, lack of knowledge and non-availability of nearby crèches as factors that limit the practice of exclusive breastfeeding, there have been little knowledge on why the practice of exclusive breastfeeding is low even among the educated. On this note, examining the practice of exclusive breastfeeding among educated working mothers has becomes apparent. This study therefore assessed the practices of exclusive breastfeeding among working mothers in tertiary institutions in Imo State.

\section{Materials and Methods}

The study was conducted in Imo State Nigeria. Imo State is in South-Eastern Nigeria with a population of about 1,951,092 (National Population Commission NPC, 2006). Imo State is located in the latitude of 5.5215 and longitude of 6.9209. Imo State is made up of three senatorial zones. There are eight (8) tertiary institutions in Imo State. They include: Federal University of Technology Owerri, Federal College of Land Resource Technology, Imo State University Owerri, Federal Polytechnic Nekedi, and Alvan Ikokwu College of Education, School of Health Technology Amaigbo, School of Nursing Orlu, Imo State Polytechnic Umuagwo.

The population of this study includes all mothers of child bearing age working in the eight tertiary institutions in Imo State. A total of one thousand (1000) working mothers were proposed as the sample size for the quantitative data of the study, however only nine hundred and twelve (912) were interviewed. This represents the sample size of this study. For the qualitative data, twenty (20) breastfeeding working mothers were interviewed.

Mixed research design was adopted for this study. The multi-stage sampling method was used for this study. Firstly, workers in tertiary institution were purposively selected because in the view of the researchers, these categories of educated people are expected to be knowledgeable about exclusive breastfeeding. Secondly, using simple random sampling method, four schools (Federal University of Technology Owerri, Imo State University Owerri, Federal Polytechnic Nekedi, and Alvan Ikokwu College of Education) were selected from the eight tertiary institutions in Imo State. Again, purposive sampling method was used to identify working mothers in the selected schools. Finally, convenience random sampling method was used to administer two hundred and fifty (250) copies of the questionnaire to the respondents in each of the selected schools; making it a total of 1000 questionnaire administer. However, only 912 questionnaire were retrieved because incomplete questions were removed during analysis. For the qualitative data of the study, convenience random sampling method was used to select five (5) working mothers each from the selected four schools for the in-depth interview section.

Questionnaire and in-depth interview were the data collection instrument adopted in the study. The questionnaire comprises of open ended and closed ended questions while interview guide was used for the in-depth interview. The content of the questions covered socio-demographic data of the respondents, awareness, practice and factors militating against the practice of exclusive breastfeeding among working class mothers in tertiary institutions in Imo State. The statistical Package for Social Science (SPSS) version 20 was used to process the analysis of the quantitative data of this study. The data was first scrutinized for possible error on the completed questionnaire by the respondents. Descriptive and inferential statistics were used to analyze the data. For the qualitative data, analysis started by reading and listening to the tape used to record data, over and over again to ensure proper transcription. After this, a coding manual was developed for the interviews, and then the data was analyzed using QDA miner Software. Some aspects of the discussions were reported verbatim to draw important insight on the discussion. The researchers got ethical clearance from Imo State University Research Ethical Committee. 


\section{Results}

Table-1. Association between Respondents Socio-Demographic Characteristics and Practice of Exclusive Breastfeeding

\begin{tabular}{|c|c|c|c|}
\hline+2 & Frequency & Percent & Pearson Chi-Square \\
\hline $20-25$ & 164 & 18.0 & \multirow[t]{6}{*}{$.000 * * *$} \\
\hline $26-30$ & 125 & 13.7 & \\
\hline $31-35$ & 174 & 19.1 & \\
\hline $36-40$ & 197 & 21.6 & \\
\hline Above 40 & 252 & 27.6 & \\
\hline Total & 912 & 100.0 & \\
\hline \multicolumn{3}{|l|}{ Marital Status } & \multirow[t]{7}{*}{$.018 * * *$} \\
\hline Single & 31 & 3.4 & \\
\hline Married & 842 & 92.3 & \\
\hline Separated & 10 & 1.1 & \\
\hline Divorced & 9 & 1.0 & \\
\hline Widowed & 20 & 2.2 & \\
\hline Total & 912 & 100.0 & \\
\hline \multicolumn{3}{|l|}{ Educational Level } & \multirow[t]{6}{*}{.319} \\
\hline Primary & 3 & .3 & \\
\hline Secondary & 47 & 5.2 & \\
\hline Tertiary & 557 & 61.1 & \\
\hline Post-graduate & 305 & 33.4 & \\
\hline Total & 912 & 100.0 & \\
\hline \multicolumn{3}{|c|}{ Spouse Educational level } & \multirow[t]{7}{*}{$.004 * * *$} \\
\hline None & 43 & 4.9 & \\
\hline Primary & 13 & 1.5 & \\
\hline Secondary & 114 & 12.9 & \\
\hline Tertiary & 443 & 50.3 & \\
\hline Post-graduate & 268 & 30.4 & \\
\hline Total & 881 & 100.0 & \\
\hline \multicolumn{3}{|l|}{ Job Status } & \multirow[t]{4}{*}{$.000 * * *$} \\
\hline Academic & 373 & 40.9 & \\
\hline None academic & 539 & 59.1 & \\
\hline Total & 912 & 100.0 & \\
\hline \multicolumn{3}{|l|}{ Spouse occupation } & \multirow[t]{6}{*}{$.000 * * *$} \\
\hline Unemployed & 45 & 5.1 & \\
\hline Civil/ Public Servant & 577 & 65.5 & \\
\hline Artisans & 66 & 7.5 & \\
\hline Traders & 193 & 21.9 & \\
\hline Total & 881 & 100.0 & \\
\hline \multicolumn{3}{|l|}{ Monthly Income } & \multirow[t]{7}{*}{$.000 * * *$} \\
\hline Below N50, 000 & 139 & 15.2 & \\
\hline $\mathrm{N} 50,000-100,000$ & 202 & 22.1 & \\
\hline $100,001-150,000$ & 367 & 40.2 & \\
\hline $\mathrm{N} 150,001-200,000$ & 135 & 14.8 & \\
\hline N200,001 and above & 69 & 7.6 & \\
\hline Total & 912 & 100.0 & \\
\hline \multicolumn{3}{|l|}{ Number of children } & \multirow[t]{6}{*}{$.008 * * *$} \\
\hline $1-2$ & 354 & 38.8 & \\
\hline $3-4$ & 455 & 49.9 & \\
\hline $5-6$ & 97 & 10.6 & \\
\hline Above 6 & 6 & .7 & \\
\hline Total & 912 & 100.0 & \\
\hline
\end{tabular}

The table 1 indicates that more $(252 ; 27.6 \%)$ of the respondents are aged between 40 years, and above, while only $125(13.7 \%)$ are aged 26-30 years. In terms of marital status, $842(92.3 \%)$ which is the majority of the respondents were married, while only $9(1.0 \%)$ were divorced.

Table 1 shows that $557(61.1 \%)$ which is majority of the respondents had tertiary education as their highest educational level, while only $3(.3 \%)$ respondents had primary education as their highest educational level. The table reveals that over half $(50.3 \%)$ of the respondents indicated that tertiary education is the highest educational level of their spouse, while $1.5 \%$ of the respondents said that primary is the highest educational level of their spouse.

In terms of job status, over half $(59.1 \%)$ of the respondents said that they are non-academic staff of their institution, while only $40.9 \%$ of the respondent said that they are academic staff of their institution. The table also 


\section{Sumerianz Journal of Social Science}

show that majority $(65.5 \%)$ of the respondents indicated that their spouse are civil/public servants, while only $5.1 \%$ of the respondents said that their spouse are unemployed.

With respect to income, over one third (40.2\%) of the respondents revealed that the earn between N100,001150,000 monthly, while only $7.6 \%$ of the respondents revealed that they earn N200,001 and above. Finally, almost half $(49.9 \%)$ of the respondents indicated that between 3-4 children, while only .7\% of the respondents revealed that they have between 6 children and above.

Among all the demographic characteristics tested, only educational level of respondents ( $\mathrm{p}$-value $=.319$ ) had no significant association with practice of exclusive breastfeeding.

To investigate whether respondents understand what exclusive breastfeeding means, the respondents were asked the meaning of exclusive breastfeeding. Table 2 shows that majority of the respondents (97.0\%) indicated that the practice of exclusive breastfeeding is about breastfeeding infants with breast milk alone for the first six months. In the IDI data, majority of the respondents said that exclusive breastfeeding is about giving the baby only breast milk for six months. In their words, a 38 years old mother of two said, I give my baby only breast milk and I will continue that till six months (Female academic staff, 38 years). Another respondent said, it is about giving a child only breast milk and it is done for the first six months without water or any other food (Female non-academic staff, 24 years). This shows that the respondents are aware of the meaning of exclusive breastfeeding.

Table-2. Respondents views on Awareness and Practice of Exclusive Breastfeeding

\begin{tabular}{l|l|l}
\hline Questions & Frequency & Percent \\
\hline Meaning of Exclusive Breastfeeding & & \\
\hline Breastfeeding infants with breast milk alone for the first six months & 885 & 97.0 \\
\hline Breastfeeding infants with breast milk and water & 22 & 2.4 \\
\hline Breastfeeding infants with breast milk and baby milk & 2 & .2 \\
\hline Breastfeeding infants with water and milk & 3 & .3 \\
\hline Total & 912 & 100.0 \\
\hline Rating of Exclusive Breastfeeding Awareness among Colleagues & & \\
\hline Low & 60 & 6.6 \\
\hline Moderate & 302 & 33.1 \\
\hline High & 503 & 55.2 \\
\hline Don't know & 47 & 5.2 \\
\hline Total & 912 & 100.0 \\
\hline Ever Practiced Exclusive Breastfeeding & & \\
\hline Yes & 500 & 54.8 \\
\hline No & 412 & 45.2 \\
\hline Total & 912 & 100.0 \\
\hline
\end{tabular}

To inquire the awareness (knowledge) level of exclusive breastfeeding among colleagues, the respondents were asked to rate level of knowledge about exclusive breastfeeding among their colleagues. Table 2 reveals that $55.2 \%$ of the respondents said that exclusive breastfeeding awareness is high among their colleagues, while only 5.2\% respondents said that they don't know. This shows that exclusive breastfeeding awareness level among working class mothers in tertiary institutions is high.

To identify those that have practiced exclusive breastfeeding and those that have not, the respondents were asked if they have ever practiced exclusive breastfeeding before. Table 2 shows that $54.8 \%$ of the respondents have practiced exclusive breastfeeding before while only $45.8 \%$ respondents said that they have not practiced exclusive breastfeeding before. This shows that over half of the respondents have practiced exclusive breastfeeding. However, in the IDI data, many of the interviewees said that they have practiced it but not up to the stipulated six months. A respondent noted:

Yes I practice it....emmm...but due to inconveniences, I don't always make it up to six months.

This is because of many issues including work, family and even the baby; because time will come when you notice that the breast milk is no long enough for the baby (Female non-academic staff, 40 years).

Another respondent said:

At my place of work, only few people practice exclusive breastfeeding. This is because some people believe that only breast milk is not enough for their babies. They believe that for baby to not be hungry, he needs to eat more than just breast milk (Female academic staff, 46 years).

To inquire what the people actually do when they say that they practice exclusive breastfeeding, a crosstabulation analysis was conducted between the respondents views on practice of exclusive breastfeeding and the length of the practice. The data is in table 3 . 
Sumerianz Journal of Social Science

Table-3. Crosstabulation of Ever Practiced Exclusive Breastfeeding and Length of Practice

\begin{tabular}{|c|c|c|c|}
\hline & Have you ever practiced exclusive breastfeeding & Total \\
\hline & & Yes & \\
\hline \multirow{4}{*}{$\begin{array}{l}\text { How long did you } \\
\text { practice exclusive } \\
\text { breastfeeding }\end{array}$} & Less than a month & $53(10.6 \%)$ & $53(10.6 \%)$ \\
\hline & 2-5 months & $277(55.4 \%)$ & $277(55.4 \%)$ \\
\hline & 6months & $167(33.4 \%)$ & $167(33.4 \%)$ \\
\hline & Above 6 months & $3(0.6 \%)$ & $3(0.6 \%)$ \\
\hline \multicolumn{2}{|l|}{ Total } & $500(100.0 \%)$ & $500(100.0 \%)$ \\
\hline
\end{tabular}

Table 3 shows that out of 500 respondents that said they have practiced exclusive breastfeeding, only $33.4 \%$ breastfed for six months. This shows that while exclusive breastfeeding awareness may be high, only few people actually complete exclusive breastfeeding for six months. This is supported by the findings of the IDI data. Majority of the interviewees said that while they consider themselves as practicing exclusive breastfeeding, they have not actually breastfed for up to six months. In the words of a respondent:

Yes I practice exclusive breastfeeding. I started to practice it after giving birth to my first child.

But I have never practiced it for complete six months which is the right thing to do. You know theory and practical is not same. After three months I start to introduce food to my baby (Female academic staff, 37 years).

To determine if there is a statistical difference between the practices of exclusive breastfeeding among academic staff and non-academic staff in tertiary institutions in Imo State, Mann-Whitney U Test was conducted.

Table-4. Mann-Whitney U Test of Job Status and Level of Exclusive Breastfeeding Practicein tertiary institutions in Imo State

\section{Ranks}

\begin{tabular}{l|l|l|l|l}
\hline & Job Status & N & Mean Rank & Sum of Ranks \\
\hline \multirow{2}{*}{$\begin{array}{l}\text { Level of exclusive } \\
\text { breastfeedingpractice }\end{array}$} & Academic & 373 & 514.56 & 191932.50 \\
\cline { 2 - 5 } & Non-academic & 539 & 416.32 & 224395.50 \\
\cline { 2 - 5 } & Total & 912 & & \\
\hline
\end{tabular}

\begin{tabular}{l|l}
\hline Test Statistics $^{\mathrm{a}}$ & Practice of exclusive breastfeeding \\
\hline Mann-Whitney U & 78865.500 \\
\hline Wilcoxon W & 224395.500 \\
\hline Z & -6.424 \\
\hline Asymp. Sig. (2-tailed) & .000 \\
\hline
\end{tabular}

From the rank section in table 4, Mean Rank of academic and none academic staff is 514.56 and 416.32 respectively. This shows that since the mean ranking for academic staff is higher than that of non-academic staff, it is likely that the prevalence of exclusive breastfeeding practice is higher among academic staff. Furthermore, from the Test Statistics section of table, $U=78865.500, P$-value $=.000$; meaning that there is a statistical significant difference between the practice of exclusive breastfeeding among academic and non-academic staff. Therefore, it can be said that academic staff in tertiary institutions in Imo State are more likely to practice exclusive breastfeeding than non-academic staff.

Table-5. Spearman's rho Correlation Test of Respondents Spouse Educational Level and Ever Practiced Exclusive Breastfeeding

\begin{tabular}{|c|c|c|c|c|}
\hline 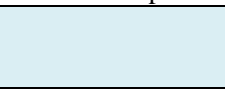 & & & $\begin{array}{l}\text { Educational } \\
\text { level }\end{array}$ & $\begin{array}{l}\text { Ever practiced } \\
\text { exclusive breastfeeding }\end{array}$ \\
\hline \multirow[t]{6}{*}{ Spearman's rho } & \multirow{3}{*}{$\begin{array}{l}\text { Educational } \\
\text { level }\end{array}$} & Correlation Coefficient & 1.000 & $.159^{* *}$ \\
\hline & & Sig. (2-tailed) & & .000 \\
\hline & & $\mathrm{N}$ & 912 & 546 \\
\hline & \multirow{3}{*}{$\begin{array}{l}\text { Ever Practiced } \\
\text { exclusive } \\
\text { breastfeeding }\end{array}$} & Correlation Coefficient & $.159^{* * *}$ & 1.000 \\
\hline & & Sig. (2-tailed) & .000 & . \\
\hline & & $\mathrm{N}$ & 546 & 546 \\
\hline
\end{tabular}

To investigate the direction of the relationship between spouse level of education and the practice of exclusive breastfeeding, Spearman's rho Correlation Test was conducted. Data in table 5 show a positive statistical significant correlation $(P$-value $=.000, r=.159)$ between respondents spouse level of education and ever practiced exclusive breastfeeding. This means that the higher one's spouse educational level, the likelihood that she will practice exclusive breastfeeding.

To identify factors that negatively affect the practice of exclusive breastfeeding among working mothers, respondents were asked to mention factors that hinder them from practicing exclusive breastfeeding. The data is in figure 1 . 


\section{Sumerianz Journal of Social Science}

Fig-1. Respondents Views on Factors That Militate Against Working Mothers Practice of Exclusive Breastfeeding

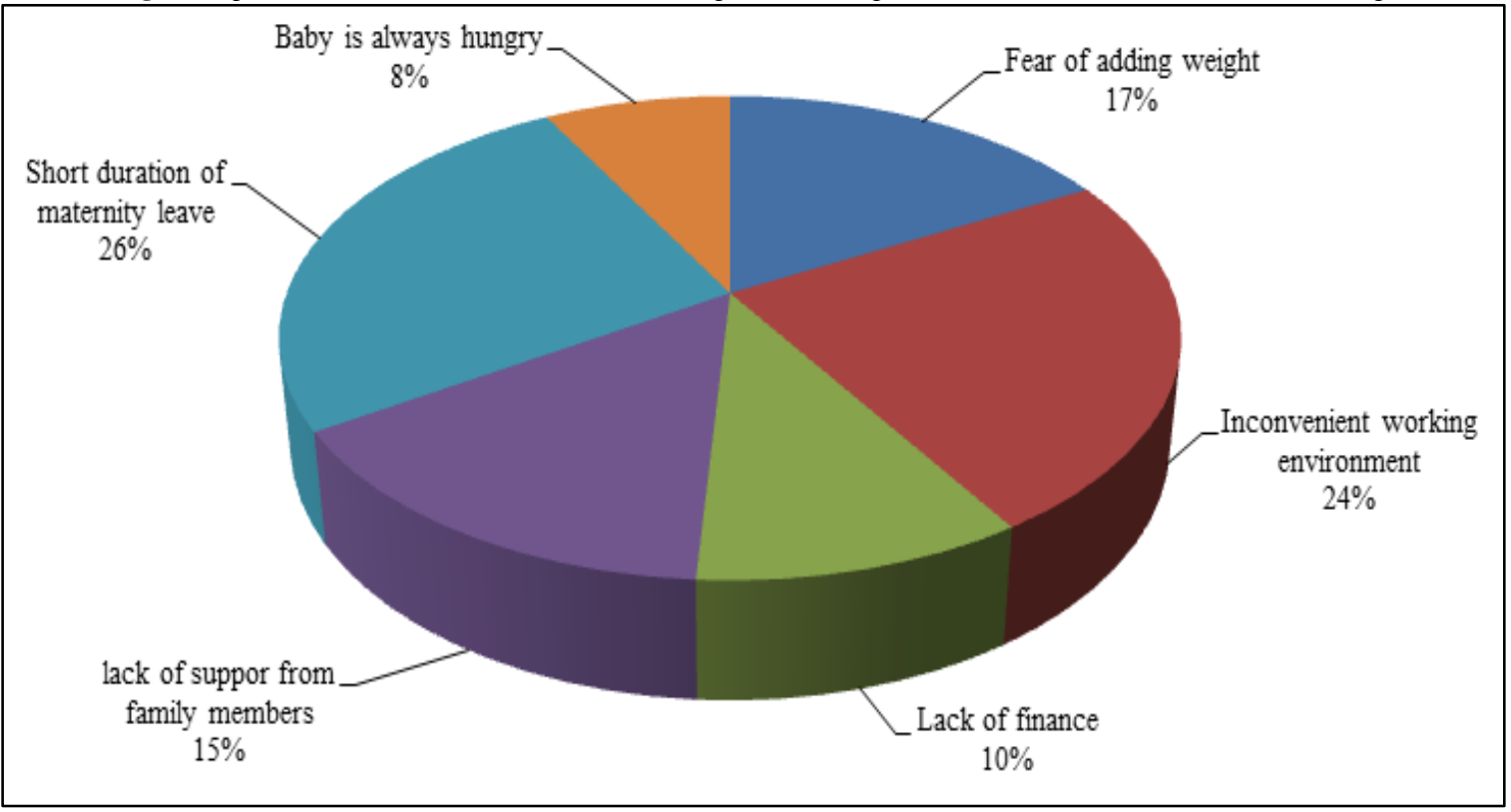

Figure 1 shows that short duration of maternity leave (26\%) and inconvenient working environment (24\%) were major factors that negatively affect the practice of exclusive breastfeeding. This is in line with the IDI data. An interviewee said:

As a working class mother in an institution like this that does not allow you to come to work with your baby, practicing exclusive breastfeeding is not easy. It is inconvenient. Some mothers would have to express the breast milk and in most cases it is unhygienic. So if the duration of maternity leave can be increased, it will help. (Female non-academic staff, 38 years).

Another respondent noted:

In our office, even when you decide to take your child to work there is no good place you will keep him of her. Is it in this small corner that we share with other colleagues, students and other people that come for our services that you will keep your child? Due to the little space available here, you that have a child know that coming to work with your child will be total distraction. It cannot work and as time goes, you will see that your colleagues will not be happy due to the noise and other inconveniences. (Female academic staff, 31 years).

\section{Discussion}

The study assessed the practices of exclusive breastfeeding among working mothers in tertiary institutions in Imo State. It was found that demographic characteristics (Age, Marital status, Spouse educational level, Job status, Income and Number of children) are associated with respondent's practice of exclusive breastfeeding. Using Spearman's rho correlation test, a positive statistical significant correlation between respondents spouse level of education and practice of exclusive breastfeeding was found. This means that the higher one's spouse educational level, the likelihood that the person will practice exclusive breastfeeding. This may be because education exposes and improves the awareness level of people about health benefits of the practice of exclusive breastfeeding. While this finding is contrary to the result of a study conducted by Adebayo et al. (2014) that found no significant relationship between education and practice of exclusive breastfeeding, the association between spouse and practice of exclusive breastfeeding is supported by existing literature. According to Omuemu and Adamu (2019), lack of spouse support is a major factor that militates against the practice of exclusive breastfeeding.

In terms of exclusive breastfeeding awareness among working mothers, the study revealed that majority of the respondents were aware of the meaning of exclusive breastfeeding. This is supported by the findings of the study qualitative data adopted in the study. Many of the respondents rated exclusive breastfeeding awareness among their colleagues high. Furthermore, the quantitative data of this study shows that over half $(54 \%)$ of the respondents have practiced exclusive breastfeeding. However, only a quarter $(33.4 \%)$ among them (Which is higher than the $18 \%$ reported by NPC in 2013) had practiced exclusive breastfeeding for six months. This was corroborated in the qualitative data section of this study. The data revealed that many of the respondents had practiced exclusive breastfeeding but not up to the stipulated six months. This shows that while many of the respondents indicated that they had practiced exclusive breastfeeding, they did not practice it for a minimum of six months as stipulated by World Health Organization. The implication is that exclusive breastfeeding practice as stipulate by World Health Organization WHO (2018) is low among working mothers in tertiary institutions in Imo State.

Using Mann-Whitney U Test, the study reveals that there is a statistical significant difference between the practice of exclusive breastfeeding among academic and non-academic staff of tertiary institutions in Imo State. The test shows that academic staff in tertiary institutions in Imo State are more likely to practice exclusive breastfeeding than non-academic staff. This may be due to the nature of their jobs; academic staff in tertiary institutions is less 
monitored and can program their working time to suit their itinerary than non-academic staff that must report to office early and leave late. This may give more time to academic staff to practice exclusive breastfeeding.

Finally, the study identified major factors that negatively affect the practice of exclusive breastfeeding among working mothers in tertiary institutions to include, short duration of maternity leave, inconvenient working environment, lack of fear of adding weight, lack of support from family members, lack of finance and feeling that breast milk is not enough for the baby. This was supported by data from the IDI section. The respondents believe that Short duration of maternity leave and inconvenient working environment were major factors that undermine the practice of exclusive breastfeeding by working mothers in tertiary institutions.

\section{Conclusion}

The study assessed the practices of exclusive breastfeeding among working mothers in tertiary institutions in Imo State. It provided some hypotheses to why the practice of exclusive breastfeeding is low among educated women in Imo State. The study also compared the practice of exclusive breastfeeding among academic and nonacademic staff working mothers in tertiary institutions in Imo State. While the awareness level of exclusive breastfeeding is high, many working mothers do not practice it due to various factors. Consequently, employers should increase paid maternity leave to minimum of six months and make work environment to be conducive for breastfeeding mothers and their babies by providing crèches to enable mothers go at intervals and breastfeed their babies. This will provide the needed time and convenient environment for working mothers to practice exclusive breastfeeding.

\section{Compliance with Ethical Standards}

Competing interest: The authors declare that there are no significant competing interests that might have influenced the performance or presentation of the work described in this manuscript.

Funding: The research work contained in the manuscript was supported by Imo State University 2018 IBRTETFUND research funding program.

\section{References}

Adebayo, A. A., Leshi, O. O. and Sanusi, R. A. (2014). Breastfeeding knowledge and practice of mothers with infants less than six months old in kosofe local government of Lagos State. Nigerian Journal of Nutritional Sciences, 35(2): 60-67.

Al-Binali, A. M. (2012). Breastfeeding knowledge, attitude and practice among school teachers in abha female educational district, Southwestern Saudi Arabia. International Breastfeeding Journal, 7(10): Available: http://doi:10.1186/1746-4358-7-10

Allen, P., Lindsay, H. and Pelto, G. H. (2005). Research on the determinants of breastfeeding duration: Suggestions for bio-cultural studies. Medical Anthropology, 9(2): 97-105.

Black, R. E., Victora, C. G. and Walker, S. P. (2013). Maternal and child undernutrition and overweight in lowincome and middle-income countries. The Lancet, 382(9890): 427-51.

Danso, J. (2014). Examining the practice of exclusive breastfeeding among professional working mothers in Kumasi metropolis of Ghana. International Journal of Nursing, 1(1): 11-24.

Dop, M. C. (2002). Breastfeeding in Africa: Will positive trends be challenged by the AIDS epidemic? . Santell, 12(1): 64-72.

Ekanem, I. A., Ekanem, A. P., Asuquo, A. and Eyo, V. O. (2012). Attitude of working mothers to exclusive breastfeeding in calabar municipality, cross river state, Nigeria. Journal of Food Research, 1(2): Available: http://dx.doi.org/10.5539/jfr.v1n2p71

Fein, S. B. and Roe, B. (2005). The effects of working status on initiation and duration of breastfeeding. American Journal of Public Health., 88(7): 1043-49.

Forbes, G. B., Adams-Curtis, L. E., Hamm, N. R. and White, K. B. (2003). Perceptions of the woman who breastfeeds: the role of erotophobia, sexism, and attitudinal variables. Sex Roles, 49(11): 379-88. Available: https://doi.org/10.1023/A:1025116305434

Global Health Observatory (2015). Exclusive breastfeeding. Available: http://www.GHO.Int

Maternity Protection Convention (2000). Convention concerning the revision of the maternity protection convention (no. 183) (revised), 1952 (entry into force: 07 feb 2002) adoption: Geneva, 88th ilc session (15 jun 2000) status: Up-to-date instrument (technical convention). Available: http://www.ilo.org/dyn/normlex/en/f?p=NORMLEXPUB:12100:0::NO::P12100_ILO_CODE:C183

National Population Commission NPC (2006). Nigeria demographic and health survey 2018. USA: NPC and ICF: Abuja, Nigeria, and Rockville, Maryland.

National Population Commission NPC, 2013. "Nigeria demographic and health survey. Rockville, md." In National Population Commission and ICF International. Accessed on 23rd July, 2017.

National Population Commission NPC (2019). Nigeria demographic and health survey 2018. Maryland, USA: NPC and ICF: Abuja, Nigeria, and Rockville.

Omuemu, V. O. and Adamu, S. A. (2019). Assessment of breastfeeding knowledge and practices among working mothers in the federal capital territory Nigeria. Int. J. Community Med. Public Health., 6(1): 20-29. Available: http://www.ijcmph.com

UNICEF (2015). Breastfeeding. Available: https://www.unicef.org/nutrition/index_action.html 
World Health Organization WHO (2018). Children: reducing mortality. Key fact, September 2018. Available: www.who.int/news-room/fact-sheets/detail/children-reducingmoratality\#_ftnref1

Yi-Chun, C., Ya-Chin, W. and Wei-Chu, C. (2006). Effects of work related factors on the breastfeeding behaviour of working mothers in a taiwanese semi-conductor manufacturer: A cross-sectional survey. BMC: Taiwan. 